\title{
Ballistic Test of Multilayered Armor with Intermediate Epoxy Composite Reinforced with Jute Fabric
}

\author{
Fernanda Santos da Luz ${ }^{a}$, Edio Pereira Lima Junior ${ }^{a}$, Luis Henrique Leme Louro ${ }^{a}$,
}

\author{
Sergio Neves Monteiro ${ }^{a *}$
}

\author{
${ }^{a}$ Departamento de Ciência dos Materiais, Instituto Militar de Engenharia - IME, \\ Praça General Tibúrcio, 80, Praia Vermelha, Urca, CEP 22290-270, Rio de Janeiro, RJ, Brazil
}

Received: November 21, 2014; Revised: July 28, 2015

\begin{abstract}
Multilayered armors with a front ceramic followed by aramid fabric $\left(\operatorname{Kevlar}^{\mathrm{TM}}\right)$ are currently used against high velocity ammunition. In these armors, a front ceramic layer that shatters and spalls the bullet is followed by an intermediate layer, usually plies of aramid fabric, which dissipates both the bullet and ceramic fragments energy. In the present work, the intermediate aramid fabric layer was replaced by an equal thickness layer of $30 \mathrm{vol} \%$ jute fabric reinforced epoxy composite. Ballistic impact test with 7.62 caliber ammunition revealed that both the plain epoxy and the jute fabric composite have a relatively similar performance of the $\mathrm{Kevlar}^{\mathrm{TM}}$ and also attended the NIJ standard for body protection. The energy dissipation mechanisms of jute fabric composite were analyzed by scanning electron microscopy and found to be the rupture of the brittle epoxy matrix as well as the interaction of the jute fibers with the post-impact fragments. This latter is the same mechanism recently disclosed for aramid fabric. However, the lightness and lower cost of the jute fabric composite are additional advantages that favor its substitution for the aramid fabric.
\end{abstract}

Keywords: ballistic test, multilayered armor, jute fabric composite, bullet penetration depth

\section{Introduction}

Bullet proof vests for personal protection may use a single layer armor with just one ballistic resistant material as that of a composite formed with plies of aramid fabric; the well known $\operatorname{Kevlar}^{\mathrm{TM}[1,2]}$. This protection, however, is limited to relatively low impact velocity $\left(\mathrm{v}_{\mathrm{i}}<600 \mathrm{~m} / \mathrm{s}\right)$ projectiles, such as a $9 \mathrm{~mm}$ ammunition. Protection against high impact velocity $\left(v_{i}>700 \mathrm{~m} / \mathrm{s}\right)$ ammunition, such as a $7.62 \mathrm{~mm}$ caliber bullet requires a multilayered armor system (MAS) $)^{3,4}$. To stand the $7.62 \mathrm{~mm}$ fast bullet with perforating power, a conventional MAS possesses a front ceramic tile, which absorbs most of the impact energy. This energy dissipation mechanism combines not only the bullet spalling but also the fragmentation of the brittle ceramic ${ }^{5,6}$. A high velocity impact projectile will also produce a blast of fragments, both from the bullet and the ceramic, with sufficient energy to inflict lethal personal trauma. Consequently, a second layer is added after the front ceramic to decrease even further the energy of the blast of fragments associated with the post-impact shock wave. In usual MAS configuration, Kevlar ${ }^{\mathrm{TM}}$ acts as the second layer and may be followed by a ductile metal sheet, like aluminum, to restrict the penetration of fragments in a body. Eventually, a spall shield covers the MAS front, before the ceramic, to avoid flight way fragments ${ }^{6}$. The use of $\mathrm{Kevlar}^{\mathrm{TM}}$ as the second intermediate layer is indicated by the aramid fiber strength around $4,000 \mathrm{MPa}^{7}$, which is much higher than any conventional material and comparable to carbon fiber. It is reported that the Kevlar ${ }^{\mathrm{TM}}$ ballistic energy

*e-mail: snevesmonteiro@gmail.com dissipation occurs by yarn rupture and elastic stretching as well as friction and pullout in the aramid fabric ${ }^{2,8}$.

Another factor affecting the energy absorbed in a MAS is the shock impedance at the interface between layers ${ }^{9}$. Upon projectile impact in the front layer, a compressivetransverse wave travels inside the ceramic and suffers multiple reflections as it crosses the other interfaces. The nature of the reflected waves depends on the impedance of the interface. A lesser dense second layer, such as Kevlar ${ }^{\mathrm{TM}}$, is associated with relatively lower shock impedance and causes the compressive component of the wave to reflect as a tensile wave $^{10}$. This contributes to an effective fragmentation of the brittle ceramic. Furthermore, the proceeding compressive wave travelling in the other MAS layers will carry a comparatively lower transmitted energy. Thus, the lesser dense is the second layer, the more efficient is the energy absorption.

Another possible second layer to be used is substitution for the Kevlar ${ }^{\mathrm{TM}}$ with even lower density could be a natural fiber reinforced polymer composite. Natural fibers, especially those extracted from plants, are used since the beginning of our civilization in simple items, such as ropes, baskets and fabrics. From the middle of last century, several natural fibers were incorporated into different matrices to be applied as engineering materials ${ }^{11}$. In past decades, an exponential growth in both research works ${ }^{12-22}$ and industrial applications ${ }^{23-25}$ has confer to natural fiber composites a prominent position owing to their technical properties (lightness, lower abrasion to molding equipments, toughness and strength) as well as economical, societal and environmental advantages ${ }^{20}$. 
Among the natural fibers, that extracted from the stem of the jute plant (Corchorus capsularis) is worldwide cultivated and has been extensively investigated in this decade as composite reinforcement ${ }^{26-32}$. The jute fiber was reported ${ }^{20}$ to present density, $1.30-1.45 \mathrm{~g} / \mathrm{cm}^{3}$ and tensile strength, 393-800 $\mathrm{MPa}$, convenient to replace synthetic fibers in polymer composites. In particular, both recycled and new fabrics made from jute fiber yarns, were found to significantly increase the Charpy and Izod impact energy of a polyethylene matrix ${ }^{33,34}$.

As for the possibility of using jute fiber composites as ballistic resistant material, Wambua et al. ${ }^{35}$ investigated the performance of polypropylene matrix reinforced with 46 vol\% of jute plain woven. Their composites were either faced or sandwiched by mild steel sheets. In terms of energy absorption, they concluded that the sandwiched (steel/composite) have advantage over neat steel and plain jute composite. Moreover, the composite dominant failure modes included delamination as well as fiber rupture and shear cut-out. Despite these relevant information, it was not the direct scope of their work ${ }^{35}$ to assess the ballistic performance of jute composites as armor for personal protection. This is for the first time conducted in the present work.

Based on the aforementioned considerations, the ballistic performance of armors composed of a front ceramic and an intermediate composite as well as a back aluminum layers was investigated in terms of depth of penetration into clay witness simulating a personal body. Ballistic tests were conducted in MAS with a front $\mathrm{Al}_{2} \mathrm{O}_{3}$-based ceramic tile. As the following intermediate layer, lighter jute fabric reinforced epoxy composite plates were compared (same thickness), to plain epoxy plates and Kevlar ${ }^{\mathrm{TM}}$. The contribution of each separated material was also assessed by individual ballistic tests. The fracture aspects of the different types of intermediated layer materials were analyzed by scanning electron microscopy.

\section{Material and Methods}

Figure 1 illustrates schematically the side view of the multilayered armor system (MAS) arrangement used in this investigation. The front layer (A), first to be hit by the projectile, was a $10 \mathrm{~mm}$ thick hexagonal tile with $31 \mathrm{~mm}$ of side dimension and made of $4 \mathrm{wt} \% \mathrm{Nb}_{2} \mathrm{O}_{5}$ doped $\mathrm{Al}_{2} \mathrm{O}_{3}$ impact resistant ceramic. Ceramic tiles were fabricated by sintering $\mathrm{Al}_{2} \mathrm{O}_{3}$ powder $(0.3 \mu \mathrm{m}$ of particle size $)$ supplied by Treibacher Schleifmittel as commercial purity (US\$ $1.59 / \mathrm{kg}$ ) mixed with $\mathrm{Nb}_{2} \mathrm{O}_{5}$ powder $(0.69 \mu \mathrm{m}$ of particle size $)$ supplied by the Brazilian firm CBMM as $99 \%$ pro-analysis (US\$ $16.13 / \mathrm{kg}$ ). Sintering was carried out at $1,400^{\circ} \mathrm{C}$ for 3 hours under air. Before tests, the clay witness was subjected to thermal treatments and evaluated according to the norm.

The intermediate layer (B) with $10 \mathrm{~mm}$ in thickness and square sides with $150 \mathrm{~mm}$ was either: (i) $\mathrm{Kevlar}^{\mathrm{TM}}$ with 16 plies of aramid fabric, or (ii) $30 \mathrm{vol} \%$ of jute fabric reinforced epoxy matrix composite (jute fabric composite for short) plate, or (iii) plain epoxy plate. The Kevlar ${ }^{\mathrm{TM}}$ was supplied by the Brazilian firm LFJ Blindagem Com. Serv. S.A. (US\$ 47.69/kg). The jute fabric was supplied by a Brazilian textile industry Lealtex Ltda. in the form of a roll (US $\$ 8.38 / \mathrm{kg}$ ). Pieces of fabric were taken from the roll, dried at $60{ }^{\circ} \mathrm{C}$ in a laboratory stove for 2 hours, and placed with the correct amount inside a steel mold. The Dow Chemical produced diglycidyl ether of the bisphenol-A(DGEBA) epoxy resin and the trietylene tetramine (TETA) as hardener were supplied by the Brazilian firm Resinpoxy (US\$ 19.35/kg). Still fluid epoxy resin mixed with phr stoichiometric fraction of the hardener was poured in between the fabric pieces onto the mold. A pressure of $5 \mathrm{MPa}$ was applied and the composite plate cured for 24 hours. Figure 2 a illustrates a plate of jute fabric composite. In a similar procedure, plain

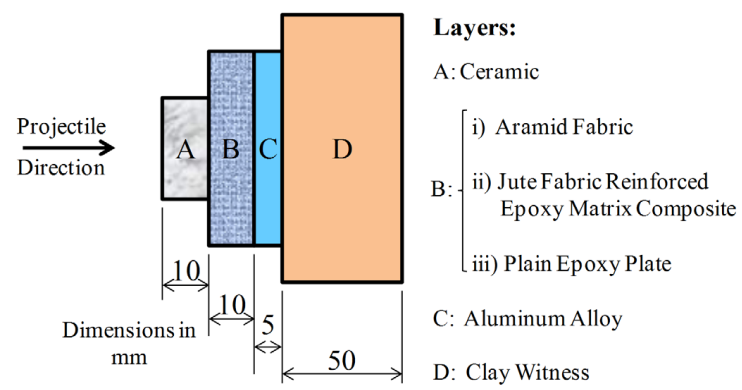

Figure 1. Schematic diagram of the multilayered armor.

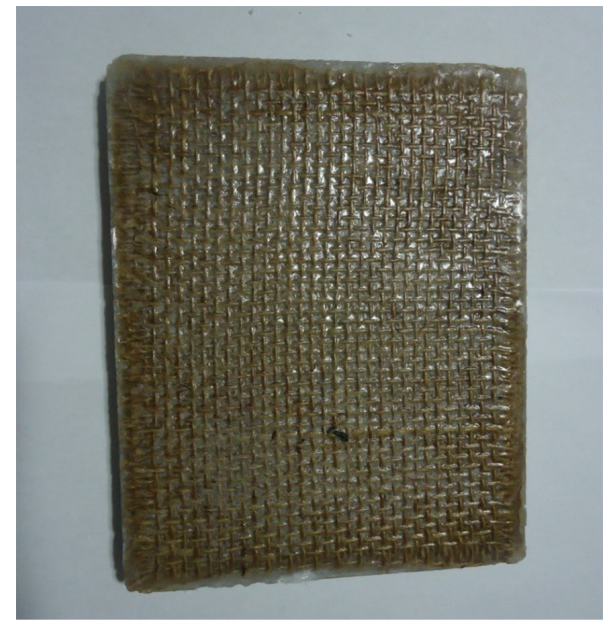

(a)

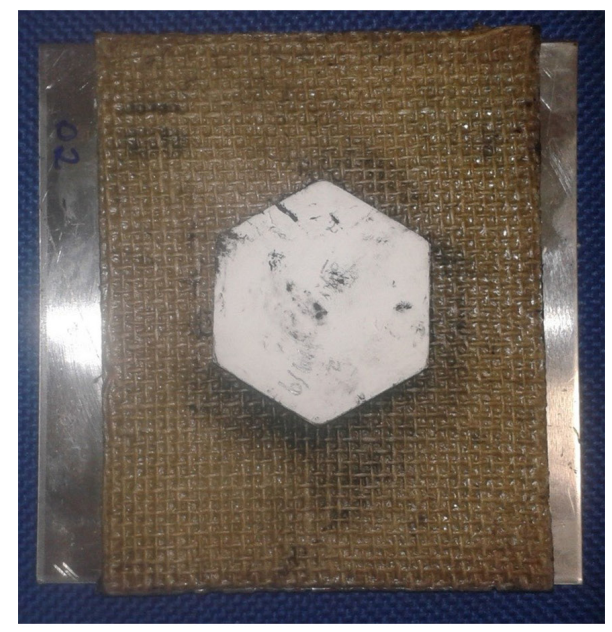

(b)

Figure 2. Plate of jute fabric composite (a) and the actual front view of a typical complete MAS investigated (b). 
DGEBA/TETA epoxy plates were also fabricated. The back layer $(\mathrm{C})$ was a $150 \times 150 \mathrm{~mm} 5052-\mathrm{H} 34$ aluminum alloy sheet with $5 \mathrm{~mm}$ in thickness, supplied by the Brazilian firm Metalak (US\$ $12.43 / \mathrm{kg}$ ). These layers were bonded in the composite with commercial Sikaflex ${ }^{\mathrm{TM}}$ adhesive supplied by the Brazilian firm Sika Co. Figure 2b shows the actual front view of a typical jute fabric composite second layer MAS target. The density of each distinct MAS component: ceramic tile $\left(3.51 \pm 0.60 \mathrm{~g} / \mathrm{cm}^{3}\right)$; jute fabric composite $\left(1.13 \pm 0.07 \mathrm{~g} / \mathrm{cm}^{3}\right)$; aramid fabric $\left(1.08 \pm 0.03 \mathrm{~g} / \mathrm{cm}^{3}\right)$ was determined by precise measurements of volume and mass in 20 samples, using Weibull statistics.

In direct contact with this metallic back layer, a block of clay witness simulated a body protected by the MAS. The clay witness was a commercially supplied CORFIX ${ }^{\circledR}$ plastilene. The trauma in the clay duplicates the plastic deformation imposed by the projectile impact on the aluminum back layer. The corresponding depth of penetration was measured with a special Mitutoyo caliper with an accuracy of $0.01 \mathrm{~mm}$, as shown in Figure 3. At least 15 measurements were performed for each test and the average/deviation values determined by means of the Weibull statistics. Eventual random and systematic errors were identified and treated as per this statistical methodology.

The ballistic tests were conducted at the Brazilian Army shooting range facility, CAEX, in the Marambaia peninsula, Rio de Janeiro. All tests, 10 for each type of MAS target, were carried out according to the NIJ 0101.06 standard using $7.62 \times 51 \mathrm{~mm}$ NATO military ammunition $(7.62 \mathrm{~mm}$ for short) with a $9.7 \mathrm{~g}$ projectile propelled from a gun barrel. Figure 4 shows, schematically, the exploded view of the ballistic test setup. A dashed straight line indicates the projectile trajectory. A steel frame was used to position the target, which was held in place by spring clips. The gun, located $15 \mathrm{~m}$ from the target, was sighted on its center with a laser beam. The exact velocity of the projectile at two moments: leaving the gun and immediately before impacting the MAS target was measured by an optical barrier, Figure 4, and a model SL-52 OP Weibel fixed-head Doppler radar system. Tests in which the target was totally perforated, allowed the residual velocity of the outcoming projectile to be measured. Fractured samples of each MAS component after the ballistic test were analyzed by scanning electron microscopy (SEM) in either a model FSM 6460 LV Jeol or a model QUANTA FEG250 Fei microscopes operating with secondary electrons at $20 \mathrm{kV}$.

\section{Results and Discussion}

All ballistic tests conducted in MAS targets failed to perforate the materials and the impact energy was dissipated inside the armor in association with a penetration depth in the clay witness, as shown in Figure 3. To evaluate the individual ballistic behavior of each distinct intermediate layer, tests were separately performed in the ceramic tile, $\mathrm{Kevlar}^{\mathrm{rM}}$, jute fabric composite plate and plain epoxy plate. In these tests, contrary to the MAS tests, the target was always perforated. Therefore, in addition to the impact velocity $\left(v_{i}\right)$, the projectile residual velocity $\left(\mathrm{v}_{\mathrm{r}}\right)$ after perforation could also be measured.

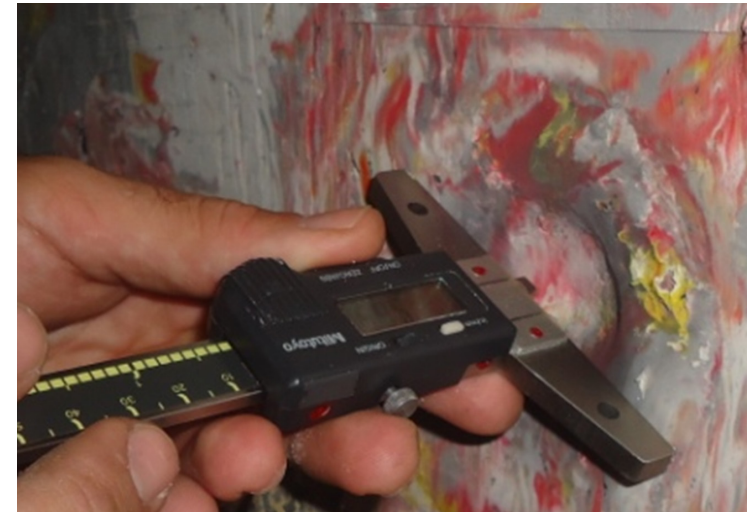

Figure 3. Measurement of the depth of penetration in the clay witness caused by the projectile impact.

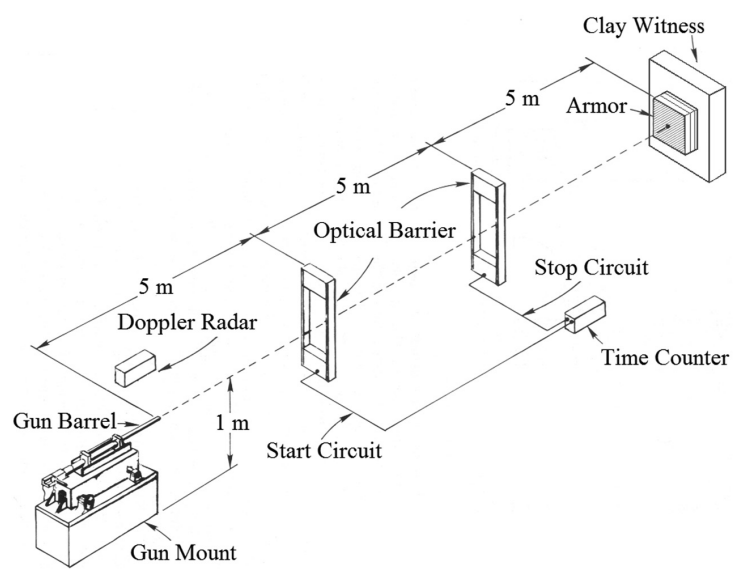

Figure 4. Schematic exploded view of the ballistic experimental setup.

Table 1 presents the average depth measured in the clay witness, Figure 3, for the different MAS targets investigated. In this table, some points are worth discussing. The three materials, tested as the intermediate layer that follows the front ceramic layer, showed corresponding penetration depth below the NIJ 0101.06 standard limit of $44 \mathrm{~mm}$ for serious body trauma. The Kevlar ${ }^{\mathrm{TM}}$, with $23 \pm 3 \mathrm{~mm}$, displays the deepest average penetration value in confront to both the jute fabric composite, with $21 \pm 3 \mathrm{~mm}$ and the plain epoxy, with $20 \pm 1 \mathrm{~mm}$. However, by considering the corresponding deviations, the three different MAS targets display similar ballistic performance. For application in armor vest, it is important to mention that the jute fabric composite is lighter and significantly cheaper than the Kevlar ${ }^{\mathrm{TM}}$. These are factors that are further discussed and might play practical advantages in considering the substitution of jute fabric composites for $\operatorname{Kevlar}^{\mathrm{TM}}$ in a MAS for personal protection against high velocity projectiles.

The projectile impact against the first MAS ceramic layer, which is responsible for most of the energy dissipation ${ }^{5,6}$ is associated with spalling of the brittle ceramic tile. In order to investigate its fracture, ceramic particles collected after the tests were observed by SEM after gold sputtering to provide an electrical conducting coating. Figure 5 shows the expected intercrystalline brittle fracture surface of a collected 
Table 1. Average depth of penetration in the clay witness backing different multilayered armors.

\begin{tabular}{cc}
\hline $\begin{array}{c}\text { Intermediate Layer } \\
\text { Material }\end{array}$ & $\begin{array}{c}\text { Depth of Penetration (significant } \\
\text { figures) from Measurements and } \\
\text { Weibull Analysis (mm) }\end{array}$ \\
\hline Kevlar $^{\mathrm{TM}}$ & $23 \pm 3$ \\
Epoxy composite & $21 \pm 3$ \\
reinforced with & \\
$30 \%$ of jute fabric & $20 \pm 1$ \\
Plain epoxy plate & \\
\hline
\end{tabular}

macroscopic ceramic particle, which is almost splitting into microscopic fragments associated with grains. Grain boundary embrittlement was caused by the $4 \mathrm{wt} \% \mathrm{Nb}_{2} \mathrm{O}_{5}$ addition to the $\mathrm{Al}_{2} \mathrm{O}_{3}$. This contributes to dissipate more energy by increasing the fractured surface. As indicated by Medvedovski ${ }^{6}$, a $7.62 \mathrm{~mm}$ projectile causes different kinds of cracks to be formed during the impact. This complex pattern of propagating cracks associated with intercrystalline fracture is observed in Figure 5.

Figure 6 shows the damage region of the $\operatorname{Kevlar}^{\mathrm{TM}}$ caused by blast of fragments resulting from the projectile impact against the front ceramic tile. The general features in Figure 6a corroborate evidences, pointed by arrows of fiber pullout from the fabric yarn, fiber stretching and fiber rupture ${ }^{2,8}$. Additionally, Figure $6 \mathrm{~b}$ reveals a massive participation of bright and white particles of $\mathrm{Al}_{2} \mathrm{O}_{3}$ attached to the fibers. This indicates that the Kevlar ${ }^{\mathrm{TM}}$ contributes in the energy dissipation by collecting ceramic fragments. Indeed, in a recent publication ${ }^{36}$, the main energy absorption mechanism of the aramid fabric in a MAS was found to consist on its fibers capacity to collect fragments by mechanical incrustation and van der Waals forces. A surprising conclusion was that the superior strength and stiffness of the Kevlar ${ }^{\mathrm{TM}}$ in a MAS is not as important as its fragment collecting capacity.

Figure 7 shows the fracture region of a jute fabric composite after penetration by fragments resulting from the projectile impact suffered by the front ceramic tile. In this Figure 7a, with higher magnification, it is observed the jute fabric separation in thinner fibrils, which is a characteristic of its mechanical rupture ${ }^{34}$. This certainly contributes to absorb the impact energy. Moreover, the fracture of the brittle epoxy matrix in Figure $7 \mathrm{~b}$ is another source of energy dissipation. Similar to what was recently reported ${ }^{36}$ and here found in the damaged Kevlar ${ }^{\mathrm{TM}}$, Figure 6b, the capture of fragments also impregnated the jute fabric composite (fiber and epoxy matrix) by bright and white particles shown in Figure 7.

Figure 8 shows the fracture of a plain epoxy after hit by fragments (projectile/ceramic) resulting from the projectile impact in the front ceramic tile. In addition to collected fragments, an important mechanism for energy dissipation in this figure is the nucleation and propagation of cracks in a typical "river pattern" characteristic of brittle polymers. Consequently, the plain epoxy rupture might also be efficient in reducing the energy or stopping fragments from the ballistic post-impact. This explains the similar depth, Table 1, as compared with the $\mathrm{Kevlar}^{\mathrm{TM}}$ and the jute fabric composite.

The contribution of each MAS component was assessed by individual ballistic tests using the same ammunition, 7.62

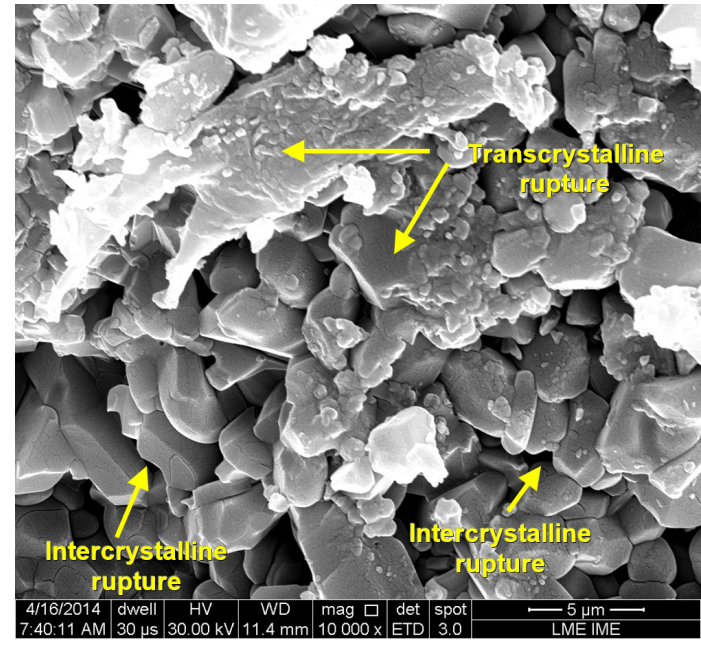

Figure 5. Fracture surface of a particle from the $\mathrm{Al}_{2} \mathrm{O}_{3}$ after the ballistic test.

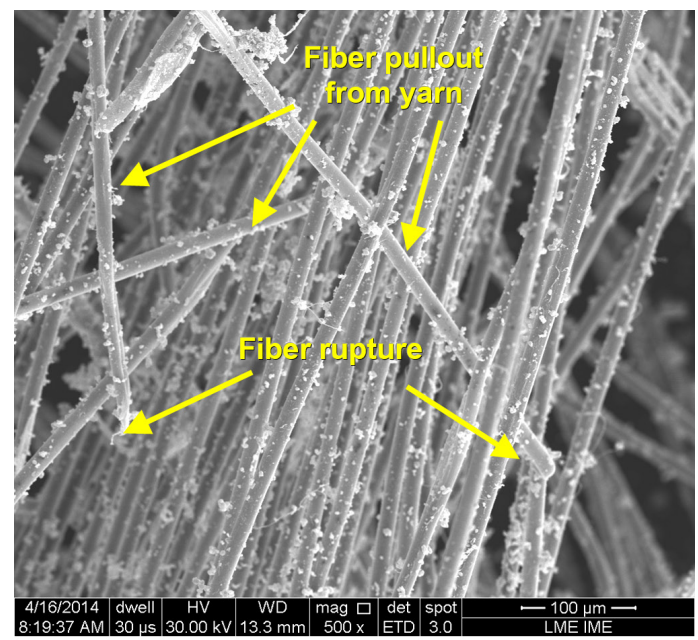

(a)

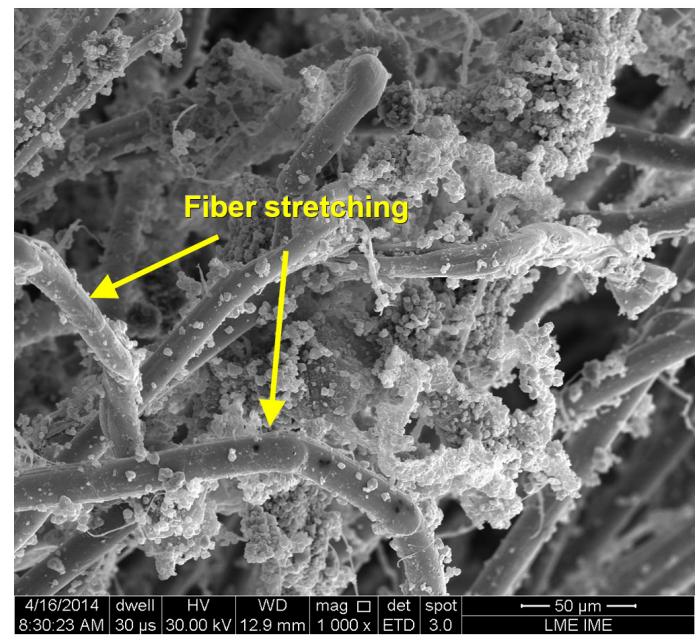

(b)

Figure 6. Damaged Kevlar ${ }^{\mathrm{TM}}$ by fragments (projectile/ceramic) after the ballistic impact: (a) lower magnification and (b) higher magnification. 


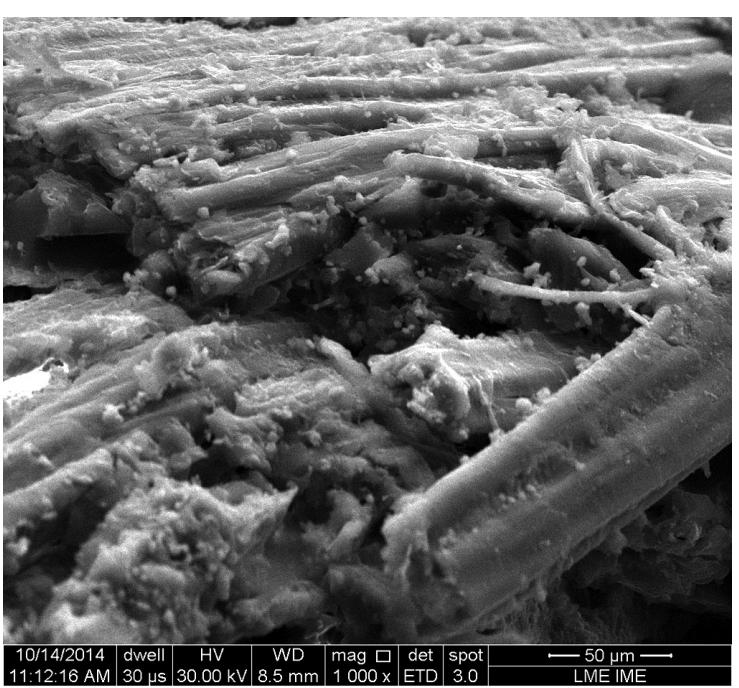

(a)

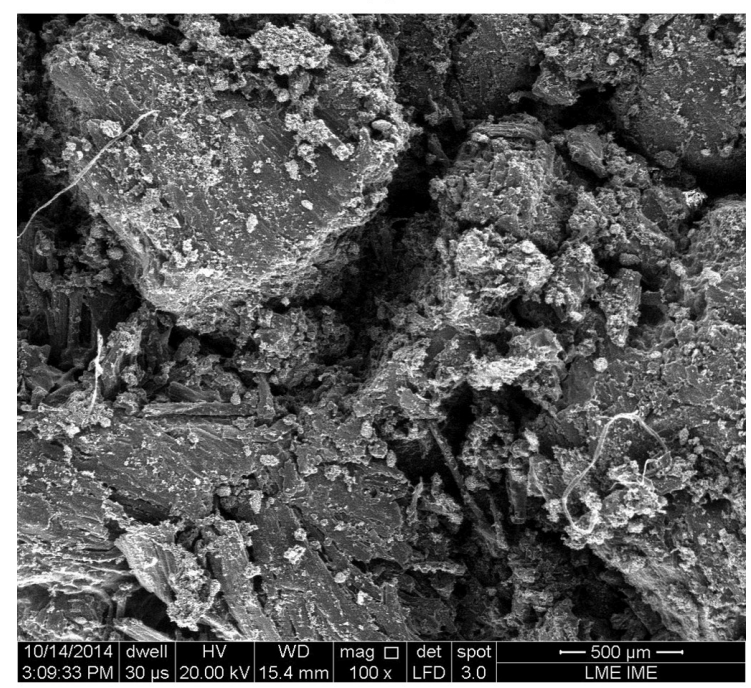

(b)

Figure 7. Fracture region of a jute fabric composite caused by fragments after the ballistic impact.

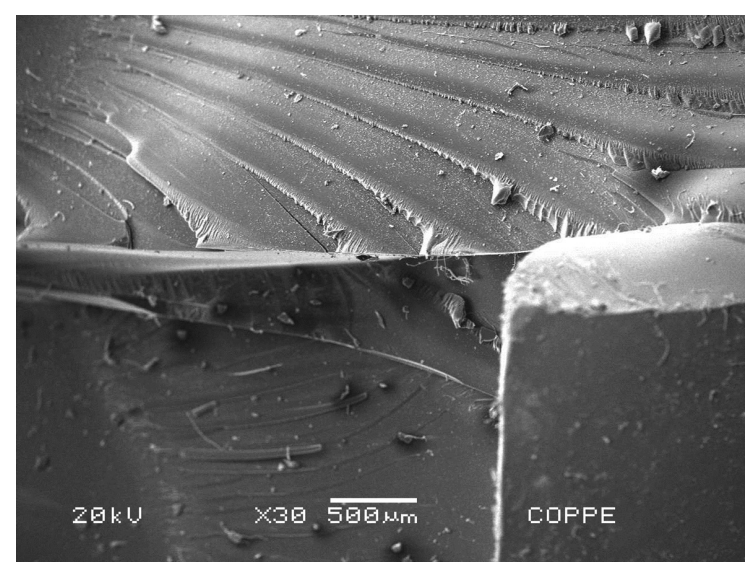

Figure 8. Fracture region of a plain epoxy caused by fragments after the ballistic impact. $\mathrm{mm}$, and methodology described in the previous section. Individual targets of the separate component layers indicated in Figure 1: $\mathrm{Al}_{2} \mathrm{O}_{3}$ ceramic tile, $\mathrm{Kevlar}^{\mathrm{TM}}$, jute fabric composite plate and plain epoxy plate, were tested in 10 samples of each. All targets were completed perforated after these individual tests. Not only the projectile impact velocity $\left(\mathrm{v}_{\mathrm{i}}\right)$ but also the residual velocity $\left(\mathrm{v}_{\mathrm{r}}\right)$ of the fragments passing through the target were measured by the Doppler radar system. The corresponding $\mathrm{E}_{\mathrm{i}}$ and $\mathrm{E}_{\mathrm{r}}$ kinetic energies were calculated by Equation 1:

$$
\mathrm{E}=\frac{1}{2} \mathrm{mv}^{2}
$$

The amount of energy $\Delta \mathrm{E}_{\mathrm{d}}$, dissipated inside the target could be estimated by Equation 2:

$$
\Delta \mathrm{E}_{\mathrm{d}}=\frac{1}{2} \mathrm{~m}\left(\mathrm{v}_{\mathrm{i}}^{2}-\mathrm{v}_{\mathrm{r}}^{2}\right)
$$

where $\mathrm{m}=9.7 \mathrm{~g}$ is the projectile mass.

Radar spectrum analyses were performed for Kevlar ${ }^{\mathrm{TM}}$, jute fabric composite and plain epoxy targets. In these cases, the residual velocities were found to be relatively closer to the corresponding impact velocities.

Table 2 presents the impact and residual velocities as well as the internally dissipated energy, Equation 1, from ballistic tests of individual MAS components. In this table, it is important noticing the more than $50 \%$ of energy dissipation in the ceramic as compared to less than $6 \%$ for the other components. The Kevlar ${ }^{\mathrm{TM}}$ dissipates the lowest amount, $(0.06 \mathrm{~kJ})$ of energy in comparison with jute fabric composite $(0.16 \mathrm{~kJ})$ and plain epoxy $(0.19 \mathrm{~kJ})$. This is coherent with the results in Table 1, where the Kevlar ${ }^{\mathrm{TM}}$ presents, in average, the lowest ballistic performance in terms of depth of penetration although within the same precision intervals for jute fabric composite and plain epoxy.

The possible explanation for this relatively low individual absorption energy of the aramid $\mathrm{Kevlar}^{\mathrm{TM}}$ in the present ballistic tests might be associated with the type of ammunition. A direct strike of a high velocity sharp-pointed $7.62 \mathrm{~mm}$ projectile penetrates easily in between a single aramid fabric weave not only breaking and stretching the fibers but also separating or pulling out the yarns. This is certainly not the case of energyreduced blunt fragments resulting from eroded and shattered $7.62 \mathrm{~mm}$ projectile after striking the front ceramic layer in a MAS. In this case, as recently revealed ${ }^{36}$ and corroborated by the present results, the Kevlar ${ }^{\mathrm{TM}}$ is an efficient MAS component to prevent personal trauma. However, both in MAS, Table 1, or individually, Table 2, Kevlar ${ }^{\mathrm{TM}}$ may not be as effective barrier to a $7.62 \mathrm{~mm}$ projectile as compared to a jute fabric composite or a plain epoxy, in which the brittle matrix is able to dissipate additional energy, Table 2, by polymer spalling.

Table 3 presents densities (measured in laboratory) and specific prices (provided by suppliers in 2015) for both fabrics, aramid and jute, as well as the plain DGEBA/TETA epoxy and the $\mathrm{Al}_{2} \mathrm{O}_{3}+4 \% \mathrm{Nb}_{2} \mathrm{O}_{5}$ ceramic. These data permitted the evaluation of weight and cost of each distinct component and total MAS target. For calculation, the face area of the ceramic (smaller hexagonal tile in Figures 1 and 2) was considered as $150 \times 150 \mathrm{~mm}$ (real situation), similar to the 
Table 2. Impact and residual velocities together with internally dissipated energy in individually ballistic tested MAS components.

\begin{tabular}{cccccc}
\hline MAS component & $\begin{array}{c}\mathbf{v}_{\mathbf{i}} \\
(\mathbf{m} / \mathbf{s})\end{array}$ & $\begin{array}{c}\mathbf{E}_{\mathbf{i}} \\
(\mathbf{k J})\end{array}$ & $\begin{array}{c}\mathbf{v}_{\mathbf{r}} \\
(\mathbf{m} / \mathbf{s})\end{array}$ & $\begin{array}{c}\mathbf{E}_{\mathbf{r}} \\
(\mathbf{k J})\end{array}$ & $\begin{array}{c}\Delta \mathbf{E}_{\mathbf{d}} \\
(\mathbf{k J})\end{array}$ \\
\hline $\mathrm{Al}_{2} \mathrm{O}_{3}$ ceramic & $848 \pm 6$ & $3.49 \pm 0.05$ & $567 \pm 43$ & $1.60 \pm 0.30$ & 1.9 \\
& & $(100 \%)$ & & $(54 \%)$ \\
Kevlar $^{\mathrm{TM}}$ & $848 \pm 6$ & $3.49 \pm 0.05$ & $841 \pm 7$ & $3.40 \pm 0.06$ & 0.06 \\
& & $(100 \%)$ & & $(1.7 \%)$ \\
Jute fabric composite & $842 \pm 7$ & $3.44 \pm 0.06$ & $835 \pm 6$ & $3.30 \pm 0.05$ & 0.16 \\
& & $(100 \%)$ & & $(4.7 \%)$ \\
Plain epoxy & $850 \pm 2$ & $3.50 \pm 0.03(100 \%)$ & $827 \pm 6$ & $3.30 \pm 0.05$ & 0.19 \\
& & & & $(5.3 \%)$ \\
\hline
\end{tabular}

Table 3. Evaluation of weight and cost of the different multilayered armor components.

\begin{tabular}{|c|c|c|c|c|c|c|}
\hline Armor component & $\begin{array}{l}\text { Volume } \\
\left(\mathrm{cm}^{3}\right)\end{array}$ & \multicolumn{2}{|c|}{$\begin{array}{l}\text { Density } \\
\left(\mathrm{g} / \mathrm{cm}^{3}\right)\end{array}$} & $\begin{array}{l}\text { Weight } \\
\text { (kgf) }\end{array}$ & $\begin{array}{l}\text { Price per kg } \\
\text { (US dollars) }\end{array}$ & $\begin{array}{c}\text { Component } \\
\text { cost } \\
\text { (US dollars) }\end{array}$ \\
\hline Ceramic tile & 225 & \multicolumn{2}{|c|}{3.51} & 0.790 & 2.18 & 1.72 \\
\hline Aramid & 225 & \multicolumn{2}{|c|}{1.08} & 0.243 & 47.69 & 11.59 \\
\hline $\begin{array}{l}\text { Jute fabric composite } \\
\text { plate }\end{array}$ & 225 & \multicolumn{2}{|c|}{$\begin{array}{c}1.13 \\
\text { Epoxy }(70 \%) 19.35\end{array}$} & 0.254 & $\begin{array}{l}\text { Jute fabric }(30 \%) \\
8.38\end{array}$ & 4.06 \\
\hline Plain epoxy plate & 225 & \multicolumn{2}{|c|}{1.30} & 0.293 & 19.35 & 5.67 \\
\hline $\begin{array}{l}\text { 5052-H34 aluminum } \\
\text { alloy sheet }\end{array}$ & 112.5 & \multicolumn{2}{|c|}{2.70} & & 12.43 & 3.78 \\
\hline \multicolumn{2}{|c|}{ Total weight with aramid (kgf) } & 1.337 & & & & 17.09 \\
\hline \multicolumn{2}{|c|}{ Total weight with jute fabric composite (kgf) } & 1.348 & \multicolumn{3}{|c|}{ Total cost with jute fabric composite } & 9.56 \\
\hline \multicolumn{2}{|c|}{ Total weight with plain epoxy (kgf) } & 1.387 & \multicolumn{3}{|c|}{ Total cost with plain epoxy } & 11.17 \\
\hline \multicolumn{2}{|c|}{$\begin{array}{l}\text { Increase in weight of MAS with jute fabric } \\
\text { composite as compared to aramid fabric }(\%)\end{array}$} & 0.82 & \multicolumn{3}{|c|}{$\begin{array}{l}\text { Decrease in cost }(\%) \text { of MAS with jute fabric composite as } \\
\text { compared to aramid fabric }(\%)\end{array}$} & 44.06 \\
\hline \multicolumn{2}{|c|}{$\begin{array}{l}\text { Decrease in weight of MAS with jute fabric } \\
\text { composite as compared to plain epoxy }(\%)\end{array}$} & 2.81 & \multicolumn{3}{|c|}{$\begin{array}{l}\text { Decrease in cost (\%) of MAS with jute fabric composite as } \\
\text { compared to plain epoxy }(\%)\end{array}$} & 14.41 \\
\hline
\end{tabular}

other MAS components. In terms of lightness, only a negligible advantage $(<1 \%)$ favors the aramid fabric. As for cost saving, the MAS with jute fabric composite is substantially cheaper than both the aramid fabric (44\%) and the plain epoxy (14\%). Based on similar depth of penetrations, Table 1, and individual dissipated energies, Table 2, one could not find a stronger reason to replace the aramid fabric for either jute fabric composite or plain epoxy in a MAS. However, the cost saving results in Table 3 support this replacement. In addition to cost saving, the reader might also see relevant advantages in favor of the jute fabric composite application in our modern society. Environmental and societal benefits are currently associated with the use of a natural fiber ${ }^{11-22}$, which is renewable, recyclable and neutral with respect to $\mathrm{CO}_{2}$ emission as well as a source of income and jobs in developing regions. These are today valuable factors to be considered for engineering applications and might contribute to change the current state of the art in MAS vests. In the present investigation, they support a preliminary indication that the jute fabric composite is the most convenient MAS second layer.

\section{Summary and Conclusions}

A multilayered armor system (MAS), in which the conventional Kevlar ${ }^{\mathrm{T}}$, following a front ceramic, was replaced by either an epoxy matrix composite reinforced with $30 \mathrm{vol} \%$ of jute fabric or plain epoxy plate attended the NIJ trauma limit after ballistic tests with $7.62 \mathrm{~mm}$ ammunition.
The ballistic performance, within the statistical deviation, was found to be similar for the three investigated MAS second layer materials. However, in perforating individual ballistic tests, the aramid fabric dissipated less energy, while the jute fabric composite and the plain epoxy are more efficient. Although not representative of what occurred in tests with MAS tests, the energy dissipated by each individual material, contribute to reveal the ballistic relevance of the epoxy rupture mechanism.

Evidence of massive collection of post-impact fragments by the jute fabric composite as well as by the aramid fabric, which was also recently reported, has been proposed as the main mechanism of energy dissipation. Additional capture of fragments and spalling of the brittle epoxy (plain or composite matrix) significantly contribute to dissipate the pos-impact energy.

Despite similar ballistic performance and negligible difference in weight, the significantly lower cost in association with environmental and societal benefits of a natural fiber, in practice, favor the substitution of jute fiber composite for both aramid and plain epoxy in a MAS.

\section{Acknowledgements}

The authors thank the support to this investigation by the Brazilian agencies: CNPq, CAPES and FAPERJ. It is also acknowledged the permission to the use of the SEM microscope by the PEMM from COPPE/UFRJ. 


\section{References}

1. Jacobs MJN and Van Dingenen JLJ. Ballistic protection mechanisms in personal armor. Journal of Materials Science. 2001; 36(13):3137-3142. http://dx.doi.org/10.1023/A:1017922000090.

2. Lee YS, Wetzel ED and Wagner NJ. The ballistic impact characteristic of $\operatorname{Kevlar}^{\circledR}$ woven fabrics impregnated with a colloidal shear thickening fluid. Journal of Materials Science. 2003; 38(13):2825-2833. http://dx.doi.org/10.1023/A:1024424200221.

3. Abrate S. Ballistic impact on composite structures. 1st ed. Cambridge: Cambridge University Press; 1998. p. 215-220.

4. Tasdemirci A, Tunusoglu G and Guden M. The effect of the interlayer on the ballistic performance of ceramic/composite armors: experimental and numerical study. International Journal of Impact Engineering. 2012; 44:1-9. http://dx.doi. org/10.1016/j.ijimpeng.2011.12.005.

5. Medvedovski E. Lightweight ceramic composite armor system. Advances in Applied Ceramics. 2006; 105(5):241-245. http:// dx.doi.org/10.1179/174367606X113537.

6. Medvedovski E. Ballistic performance of armor ceramics: influence of design and structure. Part 2. Ceramics International. 2010; 36(7):2117-2127. http://dx.doi.org/10.1016/j.ceramint.2010.05.022.

7. Callister WD Jr and Rethwish DG. Materials science and engineering: an introduction. 8th ed. New York: John Wiley \& Sons; 2010.

8. Morye SS, Hine PJ, Duckett RA, Carr DJ and Ward IM. Modeling of the energy absorption by polymer composites upon ballistic impact. Composites Science and Technology. 2000; 60(14):2631-2642. http://dx.doi.org/10.1016/S02663538(00)00139-1.

9. Louro LHL and Meyers MA. Effect of stress state and microstructural parameters on impact damage of alumina-based ceramics. Journal of Materials Science. 1989; 24(7):2516-2532. http://dx.doi.org/10.1007/BF01174523.

10. Abrate $\mathrm{S}$. Wave propagation in lightweight composite armor. Journal de Physique IV. 2003; 110:657-662. http://dx.doi. org/10.1051/jp4:20020768.

11. Monteiro SN, Lopes FPD, Ferreira AS and Nascimento DCO. Natural fiber polymer matrix composites: cheaper, tougher and environmentally friendly. JOM. 2009; 61(1):17-22. http:// dx.doi.org/10.1007/s11837-009-0004-z.

12. Satyanarayana KG, Sukumaran K, Mukherjee PS, Pavithran $\mathrm{C}$ and Pillai SGK. Natural fibre-polymer composites. Cement and Concrete Composites. 1990; 12(2):117-136. http://dx.doi. org/10.1016/0958-9465(90)90049-4.

13. Bledzki AK and Gassan J. Composites reinforced with cellulosebased fibers. Progress in Polymer Science. 1999; 4(2):221-274. http://dx.doi.org/10.1016/S0079-6700(98)00018-5.

14. Saheb DN and Jog JP. Natural fiber polymer composites: a review. Advances in Polymer Technology. 1999; 18(4):351-363. http:// dx.doi.org/10.1002/(SICI)1098-2329(199924)18:4<351::AIDADV6>3.0.CO;2-X.

15. Mohanty AK, Misra M and Hinrichsen G. Biofiber, biodegradable polymers and biocomposites: an overview. Macromolecular Materials and Engineering. 2000; 276/277(1):1-24. http:// dx.doi.org/10.1002/(SICI)1439-2054(20000301)276:1<1::AIDMAME1>3.0.CO;2-W.

16. Mohanty AK, Misra M and Drzal LT. Sustainable bio-composites from renewable resources: opportunities and challenges in the green materials world. Journal of Polymers and the Environment. 2002; 10(1):19-26. http://dx.doi.org/10.1023/A:1021013921916.
17. Netravali AN and Chabba S. Composites get greener. Materials Today. 2003; 6(4):22-29. http://dx.doi.org/10.1016/S13697021(03)00427-9.

18. Crocker J. Natural materials innovative natural composites. Materials Technology. 2008; 23(3):174-178. http://dx.doi. org/10.1179/175355508X373378.

19. John MJ and Thomas S. Biofibers and biocomposites. Carbohydrate Polymers. 2008; 71(3):343-364. http://dx.doi. org/10.1016/j.carbpol.2007.05.040.

20. Monteiro SN, Lopes FPD, Barbosa AP, Bevitori AB, Silva ILA and Costa LL. Natural lignocellulosic fibers as engineering materials: an overview. Metallurgical and Materials Transactions. A, Physical Metallurgy and Materials Science. 2011; 42(10):29632974. http://dx.doi.org/10.1007/s11661-011-0789-6.

21. Faruk O, Bledzki AK, Fink HP and Sain M. Biocomposites reinforced with natural fibers. Progress in Polymer Science. 2012; 37(11):1555-1596. http://dx.doi.org/10.1016/j. progpolymsci.2012.04.003.

22. Thakur VK, Thakur MK and Gupta RK. Review: raw natural fibers based polymer composites. International Journal of Polymer Analysis and Characterization. 2014; 19(3):256-271. http://dx.doi.org/10.1080/1023666X.2014.880016.

23. Holbery $\mathrm{J}$ and Houston D. Natural fiber reinforced polymer composites in automotive applications. JOM. 2006; 58(11):8086. http://dx.doi.org/10.1007/s11837-006-0234-2.

24. Zah R, Hischier R, Leal AL and Brown I. Curaua fibers in automobile industry: a sustainable assessment. Journal of Cleaner Production. 2007; 15(11-12):1032-1040. http://dx.doi. org/10.1016/j.jclepro.2006.05.036.

25. Njuguna J, Wambua P, Pielichowski K and Kayvantash K. Natural-fibre-reinforced polymer composites and nanocomposites for automotive applications. In: Kalia S, Kaith BS and Kaurs I, editors. Cellulose fibers: bio-and nano-polymer composites. Berlin: Springer-Verlag; 2011. p. 661-700.

26. Mohanty AK, Khan MA and Hinrichsen G. Influence of chemical surface modification on the properties of biodegradable jute fabrics - polyester amide composites. Composites Part A: Applied Science and Manufacturing. 2000; 31(2):143-150. http://dx.doi.org/10.1016/S1359-835X(99)00057-3.

27. Ray D, Sarkar BK, Das S and Rana AK. Dynamic mechanical and thermal analysis of vinylester-resin-matrix composites reinforced with untreated and alkali-treated jute fibers. Composites Science and Technology. 2002; 62(7-8):911-917. http://dx.doi. org/10.1016/S0266-3538(02)00005-2.

28. Soykeabkaew N, Supaphol P and Rujiravanit R. Preparation and characterization of jute- and flax-reinforced starch-based composite foams. Carbohydrate Polymers. 2004; 58(1):53-63. http://dx.doi.org/10.1016/j.carbpol.2004.06.037.

29. Kumar AP, Singh RP and Sarwade BD. Degradability of composites prepared from ethylene-propylene copolymer and jute fiber under accelerated aging and biotic environments. Materials Chemistry and Physics. 2005; 92(2-3):458-469. http://dx.doi.org/10.1016/j.matchemphys.2005.01.027.

30. Doan T-T-L, Gao S-L and Mäder E. Jute/polypropylene composites. I. Effect of matrix modifications. Composites Science and Technology. 2006; 66(7-8):952-963. http://dx.doi. org/10.1016/j.compscitech.2005.08.009.

31. Mohanty AK, Verma SK and Nayak SK. Dynamic mechanical and thermal properties of MAPE treated jute/HDPE composites. Composites Science and Technology. 2006; 66(3-4):538-547. http://dx.doi.org/10.1016/j.compscitech.2005.06.014.

32. Alves C, Ferrão PMC, Silva AJ, Reis LG, Freitas M, Rodrigues LB, et al. Ecodesign of automotive components making use of 
natural jute fiber composites. Journal of Cleaner Production. 2010; 18(4):313-327. http://dx.doi.org/10.1016/j.jclepro.2009.10.022.

33. Lima AC, Monteiro SN and Satyanarayana KG. Recycled polyethylene composites reinforced with jute fabric from sackcloth. Part I - preparation and preliminary assessment. Journal of Polymers and the Environment. 2012; 20(1):245253. http://dx.doi.org/10.1007/s10924-011-0373-6.

34. Lima AC, Monteiro SN and Satyanarayana KG. Recycled polyethylene composites reinforced with jute fabric from sackcloth. Part II - impact strength evaluation. Journal of Polymers and the Environment. 2012; 20:254-262. http://dx.doi. org/10.1007/s10924-011-0373-6.
35. Wambua $P$, Vangrimde $B$, Lomov $S$ and Verpoest I. The response of natural fibre composites to ballistic impact by fragment simulating projectiles. Composite Structures. 2007; 77(2):232240. http://dx.doi.org/10.1016/j.compstruct.2005.07.006.

36. Monteiro SN, Lima EP Jr, Louro LHL, Silva LC and Drelich JW. Unlocking function of aramid fibers in multilayered ballistic armor. Metallurgical and Materials Transactions A: Physical Metallurgy and Materials Science. 2015; 46(1):37-40. http:// dx.doi.org/10.1007/s11661-014-2678-2. 